\title{
Balance Ciclo de Conferencias "Formas de lo Político" en la Universidad Católica del Maule
}

\author{
Cristhian Almonacid Díaz \\ Doctor en Filosofía \\ Universidad Católica del Maule \\ Calmonacid@ucm.cl
}

\begin{abstract}
Cómo citar este artículo: C Almonacid-Díaz. "Balance Ciclo de Conferencias 'Formas de lo Político' en la Universidad Católica del Maule" en Palabra y Razón. Revista de Teología, Filosofía y Ciencias de la Religión. N $^{0} 17$ Julio 2020, pp 112-121 https://doi.org/10.29035/pyr.17.112
\end{abstract}

\section{Aspectos generales y objetivo del ciclo de conferencia "Formas de lo Político"}

En mayo del año 2019 nos reunimos académicos de filosofía y sociología para coordinar un ciclo de conferencia que decidimos llamar en ese momento "formas de lo político". Coincidimos en aquel instante que respecto al "hecho político" no sólo queríamos construir teoría, sino que, más fundamentalmente, queríamos comprometernos reflexivamente con la "praxis política". Necesitábamos reunirnos para dialogar sobre el mundo de lo político, cuando aquel fenómeno se hace polimorfo y supera ampliamente la estrechez política de la institucionalidad, que muchas veces se conforma con sacar cuentas para acceder a alguna cuota de poder estratégico.

Nuestra convicción compartida fue que lo político emerge como una actividad que nos une, teniendo en cuenta nuestro pluralismo. Porque $l o$ político es aquel mundo que nace cuando tenemos que compartir un espacio para estar juntos con otros seres humanos tan caóticamente diversos. En este sentido, lo político, paradójicamente, es un acontecimiento que reúne y al mismo tiempo separa. Dónde haya seres humanos que coincidan, se abrirá entre ellos otro espacio que solemos llamar esfera pública que únicamente puede resolverse mediante una razón dialógica, si es que descartamos la imposición de una razón sobre otra y que bajo la forma de totalitarismo puede convierte en un modo que niega toda forma de lo político.

Bajo esta perspectiva general nos fijamos el objetivo que se transformó en el hilo conductor de todas las conferencias. Nuestro propósito fue 
C Almonacid-Díaz. "Balance Ciclo de Conferencias 'Formas de lo Político' en la Universidad Católica del Maule" en Palabra y Razón. Revista de Teología, Filosofia y Ciencias de la Religión. $\mathrm{N}^{\circ} 17$ Julio 2020, pp 112-121 https://doi.org/10.29035/pyr.17.112

"generar un diálogo entre la filosofía política y la sociología, que permitan reflexiones sobre aquellos temas que urge pensar en el campo político nacional e internacional".

A este objetivo previsto, se sumó un acontecimiento fundamental. Mientras estábamos a medio camino en el desarrollo del ciclo fuimos testigos del denominado "estallido social" del 18 de octubre de 2019. La oportunidad de ser partícipes del "despertar de Chile" por medio del movimiento social que se originó aquel día, nos condujo a asumir un nuevo y renovado aliento para comprometernos como académicos en un proceso que irrumpió con tanta fuerza, que era imposible no sentirnos interpelados por la evidente necesidad de asentar nuevos compromisos sociales que permitan refundar los caminos de nuestro país para los años venideros. Aunque no contábamos ni podíamos prever los acontecimientos en nuestra planificación inicial, el estallido se convirtió en un extraordinario fenómeno de lo político. El movimiento social nos tocó directamente, nos habló y nos problematizó a partir de la manifestación del descontento, pero también a partir de la esperanza que brotaba a borbotones en las calles de Chile. La institucionalidad desbordada a causa de la convicción de los millones de ciudadanos que resignificaban los espacios públicos en aquel momento para enarbolar sus demandas de justicia social, fue la oportunidad de confirmar que lo político siempre está más allá de lo definido en la estrecha formalidad política de las instituciones.

En este ciclo se presentaron 5 conferencias a cargo de diferentes académicos e investigadores, tanto del departamento de Filosofía de la Facultad de Ciencias Religiosas y Filosóficas como del departamento de Ciencias Sociales de la Facultad de Ciencias Sociales y Económicas de la Universidad Católica del Maule. A continuación, presentamos una síntesis autorizada por parte de los conferencistas, de todas las presentaciones que se realizaron en el ciclo. Intentamos en este escrito tomar nota de los principales aspectos que cada expositor compartió ${ }^{1}$. Si bien, nuestra intención es ceñirnos ajustadamente a las palabras de los expositores, advertimos que lo que aquí exponemos es también resultado de la interpretación de quien escribe en su rol de participante.

\section{Síntesis de las conferencias}

\section{a) "Ciudadanía racional emotiva. Desactivando populismos" a cargo}

1 Para definir estas notas sobre cada conferencia nos apoyamos en las diferentes columnas de opinión que los conferencistas publicaron en la página web de la Universidad Católica del Maule durante el Segundo Semestre de 2019. Dichas columnas de opinión se pueden consultar en http:// portal.ucm.cl/noticias 
C Almonacid-Díaz. "Balance Ciclo de Conferencias 'Formas de lo Político' en la Universidad Católica del Maule" en Palabra y Razón. Revista de Teología, Filosofia y Ciencias de la Religión. $\mathrm{N}^{\circ} 17$ Julio 2020, pp 112-121 https://doi.org/10.29035/pyr.17.112

\section{de Cristhian Almonacid (Departamento de Filosofía - Universidad Católica del Maule)}

La primera conferencia en el mes de agosto nos llevó a pensar el fenómeno del populismo como una acción política que exige estar atentos a nuestras capacidades racionales emotivas, porque la política es un arte no solo de confrontación de ideas, sino que, más vívidamente, es una actividad de confrontación de afectos.

Efectivamente, si hay un concepto complejo en el escenario político actual, es el concepto de populismo. El populismo llena páginas y páginas en los medios de comunicación que no escatiman energía para denunciar el fenómeno. Es el arma perfecta en los debates políticos cuando uno de los contendientes quiere "menospreciar" o "desacreditar" a su contraparte. Adquiere más la forma de una plaga y se constituye en una emergencia que está irrumpiendo en los siempre convulsos procesos políticos en el mundo. Existen populismos de izquierdas y de derechas, pero nadie sería capaz de identificarse directamente como "populista".

Para complicarlo aún más, el populismo además de un sentido peyorativo, posee también un sentido positivo. Ernesto Laclau en su libro La razón populista pensó esta categoría como aquella noción que permite poner sobre la mesa las demandas democráticas del pueblo frente a las ideologías de los bloques dominantes minoritarios.

Más allá de este debate, la conferencia hizo la opción de presentar la categoría populismo siguiendo el sentido generalizado que ha adquirido en la actualidad. Se mencionó que el populismo se ha convertido en un método de acción política al que se recurre para conseguir adherentes, suscitar intenciones de voto y ganar elecciones. En este sentido, el populismo apela a la afección emotiva de los ciudadanos, antes que a las razones lógicas o los datos fehacientes. Un buen mensaje populista dice lo que la mayoría quiere escuchar sin acudir a la dimensión crítica, se mueve regularmente en la radicalización y busca convencer a través de una estética y particular apelación política mayoritaria.

La pregunta clave que se intentó responder fue ¿Por qué funciona el populismo en tanto método de actividad política? Se supone que, en tanto seres racionales, deberíamos mantener nuestro espíritu crítico para que prevalezca el logos ante cualquier intento de convencimiento populista desnudo de verdaderas razones. Sin embargo, la realidad se nos impone: existen discursos populistas que obtienen votos y ganan elecciones. 
C Almonacid-Díaz. "Balance Ciclo de Conferencias 'Formas de lo Político' en la Universidad Católica del Maule" en Palabra y Razón. Revista de Teología, Filosofia y Ciencias de la Religión. $\mathrm{N}^{\circ} 17$ Julio 2020, pp 112-121 https://doi.org/10.29035/pyr.17.112

A juicio del conferencista, esto sucede, porque, siguiendo a Frédéric Lordon, la política es un ars affectandi. Antes que un campo de confrontación de ideas, la política es un campo de confrontación de emociones. En la política como un ars afectandi se devela nuestra verdadera forma de racionalidad práctica en la polis. Antes que los hechos y la lógica, nuestra racionalidad elabora fórmulas afectivas para leer de la realidad social. Esto quiere decir que los conceptos no son desnudos. Las ideas políticas contienen valores, narraciones, emociones, cosmovisiones y metáforas que dan espesor significante y motivante a todas las posiciones políticas. Como diría Paul Ricoeur, la realidad social posee una estructura simbólica, por ello, toda existencia en términos sociales requiere ser primero representada antes que descrita mediante datos.

La conclusión a la que arribó la conferencia fue que hacerse cargo del funcionamiento de una racionalidad política en términos simbólicos, otorga mayores posibilidades a los ciudadanos para mantener nuestro espíritu crítico y vigilante dentro de la actividad política. Comprender la racionalidad en términos lógicos afectivos, aprovisiona a los ciudadanos para estar atentos a los mensajes políticos que quieren atraer adeptos sin capacidad de cuestionar ni proponer.

b) "El poder ciudadano: construcción de la democracia desde la sociedad civil" a cargo de Maximiliano Reyes (Doctorando en Ética y Democracia - Universidad de Valencia, España)

Esta conferencia se desarrolló a partir del desafío de la construcción de la sociedad civil, como aquel tipo de organización ciudadana no estatal que se funda en recursos morales propios, voluntarios y gratuitos que permiten garantizar la legitimidad de la democracia.

En este sentido, para el conferencista, el poder ciudadano se constituye en el requisito fundante de toda democracia. En el poder ciudadano se expresa el origen y la razón de ser de todos los procesos que permiten la construcción de la democracia. En este sentido su hipótesis de trabajo fue que la democracia comprendida como un "proceso" involucra reconocer una cualidad inherente a ella: que siempre es posible definir y redefinir el modo y la forma que adquiere la democracia a partir del ejercicio de la voluntad soberano de la sociedad civil. Gracias a lo que se denomina la "facultad cívica" inherente a la naturaleza social de la convivencia, la democracia adquiere su forma y definición específica en la orgánica política. 
C Almonacid-Díaz. "Balance Ciclo de Conferencias 'Formas de lo Político' en la Universidad Católica del Maule" en Palabra y Razón. Revista de Teología, Filosofia y Ciencias de la Religión. $\mathrm{N}^{\circ} 17$ Julio 2020, pp 112-121 https://doi.org/10.29035/pyr.17.112

Maximiliano Reyes se distancia de una comprensión de la democracia en la que se pone por delante las definiciones políticas ideológicas y en segundo plano a los ciudadanos. En este sentido, la ideologías políticas o partidistas son secundarias y dependientes del poder ciudadano, que es en realidad la única fuente de legitimidad de la democracia.

Una de las consecuencias de esta perspectiva es la duda de la autenticidad de una democracia originada bajos los preceptos determinados por un específico régimen político. Pues al establecerse los lineamientos jurídicos y legales, la democracia adquiere ciertas formas en las que la ciudadanía se hace dependiente dentro de una especie de camisa de fuerza. La democracia, bajo este punto de vista ideológico político, adquiere la forma de un instrumento para la preservación de ciertos privilegios de poder político, antes que constituirse en la expresión de una voluntad soberana de los ciudadanos.

Para evitar este riesgo, la conclusión y la invitación del conferencista fue tomar en serio la facultad cívica en la que se expresa el poder ciudadano. La ciudadanía es forjadora de la democracia en todos los espacios de la esfera pública. La participación vívida y vivificante de la sociedad cívica trasciende las delimitaciones que el sistema representativo establece. La democracia adquiere formas que manifiestan una forma de organización de la vida social antes que una pobre y mínima formalidad de la institucionalidad política.

\section{c) "Trayectorias y desvíos de los Derechos Humanos" a cargo de Sandra Vera (Departamento de Ciencias Sociales - Universidad Católica del Maule)}

En el mes de octubre, el "mes del estallido social", Sandra Vera nos invitó pensar las trayectorias y extravíos de los DDHH en el Chile democrático postransicional. No era posible prever que después de sus palabras, pronto nos lamentaríamos de las violaciones flagrantes a dichos derechos en medio de las manifestaciones sociales. Dichas violaciones patentes nos golpearon como un retroceso, que tal vez, ingenuamente, creíamos impensable e imposible después de tanta historia terrible acumulada en Chile.

Aunque no lo podía prever, Sandra Vera nos expuso sobre la distancia que existe entre el discurso sobre los DDHH en tanto pretende ser universalista y fijado a partir de definiciones abstractas y la vivencia y respeto concreto de los DDHH en el mundo social. La apreciación general 
C Almonacid-Díaz. "Balance Ciclo de Conferencias 'Formas de lo Político' en la Universidad Católica del Maule" en Palabra y Razón. Revista de Teología, Filosofia y Ciencias de la Religión. $\mathrm{N}^{\circ} 17$ Julio 2020, pp 112-121 https://doi.org/10.29035/pyr.17.112

de la conferencista fue que esta distancia se funda en lo que ella denominó (siguiendo a Didier Fassin), el triunfo de una "figura antropológica de un hombre sin derechos" propia de los siglos XX y XXI. Especialmente significativa resultó esta distinción cuando en el contexto del movimiento social iniciado el 18 de octubre, muchas personas se convirtieron en "nuevas víctimas" de la represión policial y militar que buscaba acallar la fuerza de las justas y legítimas demandas de la ciudadanía que se expresaba en las calles.

Sandra Vera, detallando cómo el discurso de los DDHH se modifica y tergiversa a partir de los acontecimientos recientes, nos hizo especial hincapié en el desplazamiento del discurso de los DDHH humanos en su origen en Chile y la situación actual. Efectivamente, el discurso sobre los DDHH nació en tiempos de la dictadura de Augusto Pinochet, gracias al "movimiento social de los DDHH" mientras se plantaba cara ante las atrocidades del autoritarismo militar. Pero después, en el momento democrático postransicional, el discurso de los DDHH se aloja en otro tipo de movimientos sociales que se fundan en procesos muy diferentes. Este desplazamiento planteado por la conferencista exige prestar atención a las diferencias discursivas entre el primer y el segundo momento, pues ambos movimientos se dan en escenarios que conllevan exigencias y significados éticos diferentes. Para Sandra Vera, una vez que se realiza esta distinción es necesario establecer algo así como "vasos comunicantes" entre ambos discursos sobre DDHH. Esta mutua comunicación entre el pasado y el presente, permite la aplicación de nuevas perspectivas para la defensa de los DDHH en tanto son exigidos por los nuevos contextos, pero al mismo tiempo permite que no se extinga en el olvido las horribles violaciones de los DDHH en época de dictadura.

Los DDHH en este sentido, no pueden ser instrumentalizados políticamente según conveniencia porque el riesgo de su banalización es muy alto. Volver a poner rostro mediante una problematización de la figura de la víctima -sacándola de una visión monolítica y pasiva- es una tarea fundamental para combatir el uso banal del discurso sobre los DDHH.

\section{d) "La crisis social ¿Es una crisis ecológica?" a cargo de Julien Vanhulst (Departamento de Ciencias Sociales - Universidad Católica del Maule)}

Después, en el mes de noviembre, nos unimos en medio de la crisis social y política para reflexionar en torno al desafío de buscar un modelo de desarrollo alternativo que nos otorgue una oportunidad de sobrevivencia a 
C Almonacid-Díaz. "Balance Ciclo de Conferencias 'Formas de lo Político' en la Universidad Católica del Maule" en Palabra y Razón. Revista de Teología, Filosofia y Ciencias de la Religión. $\mathrm{N}^{\circ} 17$ Julio 2020, pp 112-121 https://doi.org/10.29035/pyr.17.112

la crisis ecológica.

Fuimos testigos de la cortesía intelectual de Julien Vanhulst para responder reflexivamente a la fuerza de los acontecimientos sociales del momento, mediante una inflexión en sus temas de investigación para unir la problemática ecológica y la crisis social que se estaba desarrollando con tanta fuerza en Chile. Siguiendo un hilo conductor histórico el conferencista mostró cómo el tema ecológico se ha ido instalando en el debate político, conectándose cada vez más a los diferentes procesos sociales que vive el mundo. Ya en los años 60 y 70, diversos actores instalaron el tema de la sustentabilidad ecológica en medio de los movimientos sociales para llamar a la necesaria atención de los equilibrios con la naturaleza, mediante la toma de conciencia sobre los impactos ambientales que resultaban de modelos de sociedad basados en el capital, el consumo y la termo industria. La instalación del tema de la sustentabilidad socio-ecológica, en este sentido, siguió la lógica alarmista basándose en la evidencia científica, en la toma de conciencia del carácter finito del sistema tierra y en la lucha contra el escepticismo de la opinión pública que se manifestaba inicialmente insensible ante los primeros desastres ambientales causados por la intervención humana. La respuesta a este movimiento fue una rápida reacción mundial que propuso la idea de "desarrollo sostenible". Dicha idea, como un "canto de sirenas", tranquilizó las conciencias y catalizó el decurso del debate en favor de una modernización de los procesos de desarrollo económico en perspectiva aparentemente responsable con el medio ambiente. El diagnóstico de Julien Vanhulst en este sentido es demoledor, porque el discurso del desarrollo sostenible, no hizo más que reafirmar y perpetuar el mismo modelo económico, hasta adquirir la forma de un modelo cultural que no tenía entre sus principios la mitigación efectiva de los impactos ambientales. Muy por el contrario, se mitigaron las alertas y se permitió en los años 80 y 90 mantener intactas las mismas políticas socio económicas mediante el bluff del desarrollo sostenible.

Así el mundo entró en una paradoja irresoluble: el deseo de mantener el modo de vida derivado del progreso económico capitalista y de consumo, aun sabiendo que ese modelo es socialmente destructor y ecológicamente insostenible. La inconciencia colectiva inaugurada entonces se posibilita, según el conferencista, por medio de una "política de la simulación" que promete hacerse cargo de la crisis ambiental sin tocar el modelo cultural que ha causado la crisis. Se ha terminado por imponer la dominación humana sobre el planeta, lo que permite que, a comienzos de los años 2000, los expertos hablen de la inauguración de una nueva era: el "antropoceno". Este antropoceno viene a redirigir el movimiento geológico del planeta, 
C Almonacid-Díaz. "Balance Ciclo de Conferencias 'Formas de lo Político' en la Universidad Católica del Maule" en Palabra y Razón. Revista de Teología, Filosofia y Ciencias de la Religión. $\mathrm{N}^{\circ} 17$ Julio 2020, pp 112-121 https://doi.org/10.29035/pyr.17.112

afectando definitivamente a las sociedades humanas y obligando a una tardía respuesta que permita repensar el lugar de la humanidad dentro del ecosistema.

Responder a los riesgos socio-ambientales del modelo económico y político es la tarea pendiente. La emergencia del antropoceno obliga a la humanidad, no solo a mejorar las formas de control sobre la naturaleza, sino que abrirse a un cuestionamiento profundo acerca de la capacidad que tengan los seres humanos para cambiar la forma de vida que se ha desarrollado hasta ahora.

Las desigualdades sociales en este sentido, bajo la perspectiva de Julien Vanhulst, son también un resultado de este modelo capitalista y de consumo. El modelo causa la desigualdad en términos ecológicos y perpetua las desigualdades sociales porque no ha cumplido su promesa de prosperidad, paz y verdadera libertad, poniendo en riesgo la convivencia de los seres humanos entre sí y de los seres humanos con su medio ambiente. En este sentido, para Julien Vanhulst, la crisis ecológica y la crisis social son cara de una misma moneda, dos manifestaciones de un mismo problema, a saber, la desigualdad y la injusticia que se han perpetuado en un modelo capitalista neoliberal, instalado en el corazón de nuestras sociedades sin otra alternativa. Solamente una verdadera y profunda transformación sociocultural y económica, podría ofrecer una oportunidad para superar estas inequidades ecológicas y sociales que se han vuelto estructurales.

\section{e) "La Universidad Imposible", a cargo de Javier Agüero (Departamento de Filosofía - Universidad Católica del Maule)}

Por último, en el mes de diciembre de 2019, la invitación de Javier Agüero fue a pensar la Universidad y a nosotros mismos en tanto comunidad universitaria como un acontecimiento abierto al desafío de construirnos (o de-construirnos) a partir de lo no previsto, de lo que no podríamos siquiera proyectar.

La reflexión a la que nos condujo Javier Agüero tuvo como objeto de atención a "la Universidad", entendida en términos generales, como aquella institución sin apellido, es decir, la universidad en tanto sustantivo. El punto de partida de su conferencia fue precisar una crítica a las perspectivas homogeneizantes que se han impuesto en el tiempo presente sometiendo la tarea de la universidad. Dichas perspectivas se han impuesto por medio de las exigencias cuantitativas de la productividad científica individual, que pone como única meta la indexación de las publicaciones 
C Almonacid-Díaz. "Balance Ciclo de Conferencias 'Formas de lo Político' en la Universidad Católica del Maule" en Palabra y Razón. Revista de Teología, Filosofia y Ciencias de la Religión. $\mathrm{N}^{\circ} 17$ Julio 2020, pp 112-121 https://doi.org/10.29035/pyr.17.112

en pos de incrementar el impacto numérico de un pretendido resultado exitoso. Este modelo de trabajo académico e investigativo efectista, a juicio del conferencista, proviene del modelo neoliberal que se ha incrustado también en el seno de la universidad. Han tambaleado con ello los verdaderos fines de la universidad en términos de generación de conocimiento, de fortalecimiento de las comunidades científicas a través de un espíritu solidario y la mutua colaboración en el avance de un saber que se ambiciona como dador de sentido. Sin embargo, la universidad parece haber entrado, sin crítica ni resistencia, a la neoliberalización de sus procesos para transformarse en una estructura técnica y tecnificante más dentro del engranaje de la producción del mercado.

En este punto Javier Agüero se pregunta: ¿Es posible para la Universidad salir de este proceso de tecnificación irreflexiva?

La respuesta a esta pregunta en la conferencia se inauguró recurriendo al pensamiento de Jacques Derrida. La "razón de ser" de la universidad, según Derrida, está ligada a la misión o destinación futura hacia donde la universidad camina. Esta misión se justifica mediante las razones que fundamentan y se convierten la causa del ser de la universidad. Esta causa está profundamente arraigada en la actitud crítica que le permite a la universidad llegar a ser un espacio permanente para el debate, la disociación y la necesaria polémica para colaborar verdaderamente en la transformación de la sociedad.

Dicha transformación de la universidad y de la sociedad en su conjunto ¿Dónde está? ¿Quién la ve con claridad? ¿En qué consiste? ¿Cuál es la transformación que se necesita? Este es el núcleo propositivamente problemático que, a nuestrojuicio, le sirve a Javier Agüeropara la articulación con aquellas dimensiones no calculadas del ser y del quehacer universitario. En la categoría de la imposibilidad entran todas aquellas cuestiones no previstas ni posibles, que hacen de la universidad una institucionalidad "imposible". Para explicarlo, nuestro conferencista recurre también al pensamiento de Derrida, quien piensa que lo imposible y lo posible, no se constituyen en categorías contrarias, sino que son dos momentos de un mismo proceso aporético: sin abandonar la razón de ser de una universidad en términos de lo que le es posible ser, la universidad debe abrirse a lo imposible, en términos de caminar hacia los confines de la emancipación de sus propias posibilidades. Así vistas las cosas, la universidad no sólo es una institución del saber, sino que también del aprender. La universidad no es sólo la institución de las certezas, sino también del error y de la duda. La universidad no solamente es una estructura homogénea de sentido, sino que 
también es una comunidad de vida científica donde importan la diferencia y la diversidad de opiniones. La universidad no solamente responde a una tradición, sino que también responde a lo nuevo que ha de venir. Por último, la universidad no responde únicamente a un cierto orden racional, sino que también responde a las irracionalidades del quehacer humano. Por todo ello, la universidad como imposible necesita reservarse el derecho a "decirlo todo", sin condiciones. Así vistas las cosas, cualquier tipo de restricción en el decir, es una contradicción interna del ser imposible de la universidad que se dirige no siempre a la verdad como meta, sino que a la verdad como horizonte. La universidad imposible es también el espacio privilegiado para la irresolución, la perplejidad y el dilema.

\section{3.- Agradecimientos}

Nos queda agradecer a la Facultad de Ciencias Religiosas y Filosóficas, a la Facultad de Ciencias Sociales y Económicas, al Centro de Investigación en Religión y Sociedad (CIRS), al Centro de Estudios Urbano Territoriales (CEUT), al Centro de Extensión y al Departamento de Comunicaciones de nuestra universidad. Nuestro compromiso es continuar pensando juntos las formas de lo político, porque es una necesidad ineludible y ahora con mayor razón que antes. Pensar políticamente es esencial para asegurar la vida juntos en este espacio que constituimos con sentido histórico y para sostener la convivencia que nos permite aferrarnos a la riqueza de la diferencia y al deber de ejercer nuestra libertad que adquiere sentido junto con otros. Un reconocimiento especial a cada uno de nuestros conferencistas y un agradecimiento a quienes nos honraron con su activa presencia y participación en cada conferencia. 